Research Paper

\title{
Evaluation of the safety and efficacy of radiofrequency ablation for treating benign thyroid nodules
}

\author{
Xiaoyin Tang, Dan Cui, Jiachang Chi, Zhi Wang, Tao Wang, Bo Zhai ${ }^{\bowtie}$, Ping Li $^{凶}$ \\ Department of Interventional Oncology, Renji Hospital, School of Medicine, Shanghai Jiaotong University, Shanghai, China. \\ $\bowtie$ Corresponding authors: Ping Li, liping@renji.com; Bo Zhai, zhaibo@renji.com. \\ (c) Ivyspring International Publisher. This is an open access article distributed under the terms of the Creative Commons Attribution (CC BY-NC) license \\ (https://creativecommons.org/licenses/by-nc/4.0/). See http://ivyspring.com/terms for full terms and conditions.
}

Received: 2016.09.21; Accepted: 2016.11.27; Published: 2017.02.25

\begin{abstract}
Background: Radiofrequency ablation (RFA) is a relatively new procedure for treating benign thyroid nodules. The purpose of this study was to evaluate the safety and efficacy of RFA for treating benign thyroid nodules so as to serve as a reference for future clinical practice.

Methods: This study retrospectively analyzed the clinical data of patients receiving percutaneous RFA for treating thyroid nodules from November 2014 to July 2015 in our medical center. One hundred and eight patients with a total of 380 nodules received ultrasound-guided RFA for treating thyroid nodules. Comparisons of the volume change of thyroid nodules before and after RFA treatment, post-treatment complication, and change of thyroid function, were carried out afterwards.

Results: Before treatments, all patients received fine needle aspiration biopsy (FNA) which supported the diagnosis of benign tumor. There were 13 males and 95 females included in the study. Twenty-six cases $(24.07 \%)$ had single nodule, and 82 cases $(75.93 \%)$ had multiple nodules. Before treatments, the thyroid functions (FT3, FT4, and TSH) were normal originally or adjusted to normal range by endocrinology treatment. The preoperative nodules had minimum volume of $0.01 \mathrm{~mL}$, maximum volume of $70.89 \mathrm{~mL}$, and mean volume of $1.02 \pm 4.24 \mathrm{~mL}$. The volume of nodules one month and three months after RFA were $0.29 \pm 0.72 \mathrm{~mL}$ and $0.15 \pm 0.87 \mathrm{~mL}$, respectively. In addition, volume reduction ratio (VRR) of nodules one month and three months after RFA were $64.12 \%$ and $85.54 \%$, respectively. Both volume of nodules and VRR had statistically significant differences for pre-operative and post-operative comparison $(\mathrm{P}<0.05)$. Thyroid functions were in normal range after treatments, and there was no serious complications.

Conclusions: Ultrasound-guided RFA treating benign thyroid nodules had the advantages of definite efficacy, safety, strong in control ability, no incision, less damage to surrounding normal tissues and no effect on thyroid function. It can be used as one of the main treatment methods for treating benign thyroid nodules.
\end{abstract}

Key words: Radiofrequency ablation, benign thyroid nodule, safety, efficacy.

\section{Introduction}

Thyroid nodule is a common disease, and the presence of thyroid nodulewas about $4-7 \%$ in population[1, 2]. With the advancement of CT, MRI, high-resolution ultrasound, isotope scanning and other medical imaging technologies, many hidden thyroid nodules can now be found $[3,4]$. The risk of thyroid nodules, which had more prevalence in women, was increased by age, and it was related to abnormal intake of iodine and exposure to ionizing radiation $[5,6]$. Biopsy had showed that benign thyroid nodule had the potential of canceration, and there was no significant difference between the risk of becoming thyroid cancer (about $4 \% \sim 6.5 \%$ ) and volume of nodules [6]. Recent studies have found that even thyroid solid nodules which were diagnosed by fine-needle aspiration as benign lesions still had $6 \%$ 
possibility of being malignant lesions diagnosed by surgical pathology [7]. Therefore, active treatments should be conducted for suspected malignant thyroid nodules diagnosed by clinical and imaging examinations [8]. Treatment are also needed for some benign nodules due to compression symptoms caused by large volumes, local uplift affecting appearance, or possibility of malignancy [9]. Traditional treatments include surgery or medication. Surgical treatment was not accepted by some patients due to severe injury, relative high incidence of complications (such as a certain proportion of recurrent laryngeal nerve injury), permanent scar in the neck, reduced thyroid function by resecting normal thyroid tissue at same time, and long-term drug treatment for some patients. Thyroid hormone replacement therapy, in some degree, can treat hypothyroidism due to excessive resection of thyroid tissue.However, the efficacy of drug treatment is also controversial, andsome literature repored that levothyroxine had no obvious effects ininhibiting nodules[10]. Radiofrequency ablation (RFA), as a new minimally invasive treatment techonology developed in recent years, had been applied frequently in the treating abdominal cancer[11, 12]. With the maturation of this technology, RFA has been successfully applied in treating benign thyroid nodules or recurrent thyroid cancer in foreign countries[13, 14]. Because RFA has the advantages of minimally invasive, effective, safe, economic and good appearance, the Task Force Committee of the Korean Society of Thyroid Radiology recommended optimal use of RFA for thyroid nodules in the year 2012[15].Due to late start, there were relatively less related reports of RFA treating thyroid nodules in China[16]. The purpose of this study is to analyze the safety and efficacy of RFA for treating benign thyroid nodules, which can served as a reference for future clinical practice.

\section{Materials and Methods}

\section{Case Material}

\section{Patient Material}

From November 2014 to July 2015, one-hundred-and-eight patients received ultrasound-guided percutaneous RFA for treating thyroid nodules in Department of Interventional Oncology, Ren Ji Hospital, School of Medicine, Shanghai Jiao Tong University. Patients' ages: youngest: 22 years old; oldest: 84 years old; average age: $52 \pm 14$ years old. The RFA treatment was approved by the ethics committee of the hospital. Consents for accepting RFA and anesthesia, which provided detail explanations of the risks of anesthesia and surgical complications, were signed by patients before operations.

\section{Inclusion criteria}

(1) Before treatment, the results of the patient'sroutine blood testsand blood coagulation functions were normal, and thyroid function was normal or adjusted to normal range by endocrinology treatment;

(2) Patients with normal chest X-ray and electrocardiogram;

(3) Preoperative ultrasound suggested benign thyroid nodules (TI-RADS type 3 and type 4a), and pathological diagnosis was benign by ultrasound-guided fine-needle aspiration biopsy of thyroid;

(4) Patients voluntarily recevied RFA with strong will;

(5) There wereforeinbody sensation in neck,compression symptom due to relative large volume, local uplift affecting appearance, and worries of malignant lesions.

\section{Exclusion criteria}

(1) Patients who were diagnosed with malignant thyroid tumor by preoperativefine-needle aspiration cytology;

(2) Females during pregnancy or lactation.

(3) Patients accompanied by severe systematic diseases, such as severe coagulation disorders, myocardial infarction, stroke, cancer, connective tissue diseases (scleroderma and systemic lupus erythematosus), systematic infection, and uncontrolled diabetes.

(4) Patients with serious physical, neurological and psychiatric diseases.

\section{Preoperative preparation and ablation process of RFA}

2.1 All patients underwent high frequency ultrasound forthyroid assessment:

The indicators were: morphology of thyroid nodules(regular/irregular), aspect ratio of nodules $(<1 / \geq 1)$, nodular edge (clear / unclear), echo type (non hypoechoic/hypoechoic), posterior acoustic type (no attenuation /attenuation), echotexture (homogeneous/heterogeneous), internal blood flow (no/yes), microcalcifications (without /with), and neck lymph node metastases (without / with).

\subsection{Equipment}

Ultrasound adopted Twice US system (Esaote, Italy), L522 and L523 probe, $7-10 \mathrm{MHz}$ center frequency, with CEUS function. US contrast agent was SonoView (Sine Pharma, Italy). RFA treatment 
system was Medsphere RF Generator S-500 (Medsphere, Shanghai, China).

\subsection{Operation of RFA}

All the operations were carried out in standard surgical operating roomunder general anesthesia with tracheal intubation. After anesthesia, shoulder and neck pillow were put under patients' shoulder and neck, respectively. Neck hyperextension positionwas adopted, and routine prep and draping were applied. Before RFA, methylprednisolone were given to patientprophylactically. The power was set to $10-15 w$, and impedance mode was used.The midline of the neck near the thyroid isthmus was the preferred needle puncture site, and ultrasound-guided radiofrequency electrode was pierced into bottom of tumor body through thyroid nodule.After startingRFA device, gasification phenomenon around electrodecould be seen until tumor was completely covered with strong echo.For relative large nodules, whensingle point ablation could not achieve effective ablation range, multi-plane puncture and multi-level ablation were applied by adjusting electrode direction and ablation plane until tumor was completely covered with strong echo in three-dimensional space.CEUS technologywas usedto for real-timeevaluation of ablation of thyroid nodules. If the internal of nodules still had some areas of enhancement, prompt complementary ablation could be applied to avoid residual nodules to the maximum degree. After ablation, contrast-enchanced ultrasound was performed to observe perfusion of contrast agents inside thethyroid nodules.

\section{Postoperative review and follow-up}

\subsection{Time Settings}

Follow-up one month and three months after ablation, and time was within \pm 5 days.

\subsection{Follow-up contents}

3.2.1 After ablation, regular follow-up of patients' general conditions was conducted, and occurrence of complications were recorded.

3.2.2 One month and three months after ablation, high-frequency ultrasound and ultrasound imaging were carried out to observe the volume of the ablation lesion in the thyroid, echo type (non hypoechoic/hypoechoic), internal blood flow (no/yes), and perfusion of contrast agent (no/yes). The evaluation of efficacy of ablation was based on whether thyroid nodule was completely abalated and volume change of ablation lesion. If contrast-enhanced ultrasound had showed no perfusion inside ablation lesions, it suggested complete ablation. If some area of ablation lesion had local perfusion, it suggested residue of ablation lesions. Then all patients were followed up by telephone every 3 months. And the follow-up ended in June 2016.

3.2.3 Volume measurement of thyroid nodules: measuring volume of nodules through two-dimensional ultrasound

V=парс / 6 (a: transverse diameter of nodule, b: vertical diameterof nodules, c: anteroposterior diameter of nodules).

3.2.4 Volume reduction ratio(VRR)could reflect reduction of ablation lesions after ablation of thyroid nodules.

\section{$\operatorname{VRR}(\%)=($ Initial Volume $(m L)-$ Final Volume $(m L)) /$ Initial Volume $(\mathrm{mL}) * 100 \%$}

VRR1: reduction rate of ablation lesions one month after ablation

VRR2: reduction rate of ablation lesions three months after ablation

3.2.5 Complete ablation rate $(\mathrm{CAR} \%)=$ Number of nodules achieved complete ablation (N)/ Total number of nodules $(\mathrm{N}) \times 100 \%$

\section{Statistical analysis}

SPSS 17 (version: 2008-8-23) running in windows 8 was adopted to make statistical analysis. Change of indicators, such as thyroid function, volume of nodules, and VRR before operations, at one month and three months after ablation,were compared. Quantitative data was displayed as $\mathrm{x} \pm \mathrm{s}$. P $<0.05$ indicated that there was statistically significant difference in data.

\section{Results}

There were 108 patients with a total of 380 nodules included in this study. Of which, 13 males and 95 females with male to female ratio of 1:7.3. Average age was $52 \pm 14$ years old. Twenty-six cases $(24.07 \%)$ had single nodule, and 82 cases $(75.93 \%)$ had multiple nodules.

\section{Safety}

Ablation processes were successful without serious bleeding, skin burns or serious thyroid storm.

Before ablation, the minimum volume of nodules was $0.01 \mathrm{~mL}$, themaximum volume was $70.89 \mathrm{~mL}$, and the average volume was $1.02 \pm 4.24 \mathrm{~mL}$. The shortest ablation time and the longest ablation time were 2 seconds and 1200 seconds, respectively, and average ablation time was $52.4 \pm 143.1$ seconds. Ablation time of thyroid nodule was significantly related to nodule volume $(\mathrm{P}<0.01)$ (see Figure 1 for details). 


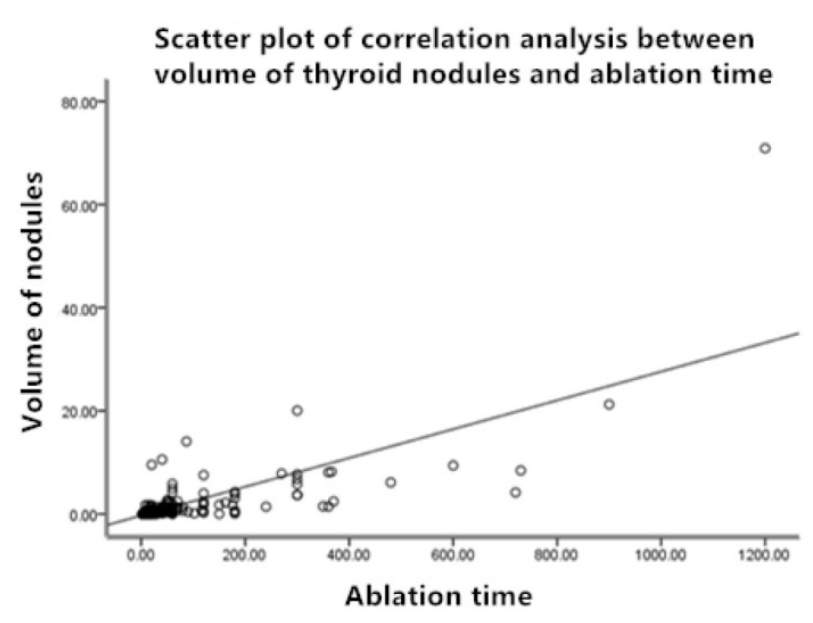

Figure 1. Scatter plot of correlation analysis between volume of thyroid nodules and ablation time.

All patients were discharged successfully on the first day after ablation without significant complaints of pain.

Postoperative thyroid function were within normal range without hypothyroidism.

\section{Efficacy}

The volume of nodules before ablation, at one month and three months after ablation were1.02 \pm 4.24 $\mathrm{mL}, 0.29 \pm 0.72 \mathrm{~mL}$, and $0.15 \pm 0.87 \mathrm{~mL}$, respectively. There was statistically significant difference $(\mathrm{P}<0.05)$. Figure 3 showed the volume change of nodule after RFA comparing to before ablations.

The volume reduction ratio (VRR) of thyroid nodulesat one month and three months postoperatively were $64.12 \%$ and $85.54 \%$, respectively. There was statistically significant difference $(\mathrm{P}<0.05)$ (See Table 1 for details).

Three hundred and seventy-six nodules out of the total three hundred and eighty nodules were completely ablated, and the remaining four nodules were partly ablated. The complete ablation rate was $98.95 \%$.

Because the four partly ablated nodules were adjacent to trachea and recurrent laryngeal nerve with relative large volume, explanations were given to patients preoperatively that only partial ablation would be conducted to reduce tumor so as to relive compression symptom. After ablation, the compression symptoms were relived, and patients were satisfied with the treatment results. The remaining nodules achieved complete ablation.

Table 1. Change of average volume of nodules and VRR.

\begin{tabular}{lllll}
\hline & $\begin{array}{l}\text { Before } \\
\text { ablation }\end{array}$ & $\begin{array}{l}\text { One month } \\
\text { after } \\
\text { ablation }\end{array}$ & $\begin{array}{l}\text { Three month } \\
\text { after ablation }\end{array}$ & P \\
\hline $\begin{array}{l}\text { Average volume } \\
\text { of nodules }(\mathrm{mL})\end{array}$ & $1.02 \pm 4.24$ & $0.29 \pm 0.72$ & $0.15 \pm 0.87$ & $<0.05$ \\
VRR & & $64.12 \%$ & $85.54 \%$ & $<0.05$ \\
\hline
\end{tabular}

Volume of nodules $(\mathrm{mL})$ showed as $\mathrm{x} \pm \mathrm{s}$

VRR: the volume reduction ratio

\section{Complications}

There were no bleeding, infection, nor skin injury occurred after ablation. A total of $12(11.11 \%)$ minor complications were observed during follow-up, including mild sore throat in eleven cases $(10.19 \%)$, and temporary vocal cord paralysis in one case $(0.92 \%)$. All of the 12 patients fully recovered naturally within three months.

The eleven cases, which suffered mild sore throat, were relived within three days.

One case had temporary vocal cord paralysis displaying as hoarseness and coughing during drinking postoperatively. Coughing during drinking symptom disappeared two weeks after ablation while hoarseness disappeared two months after ablation.
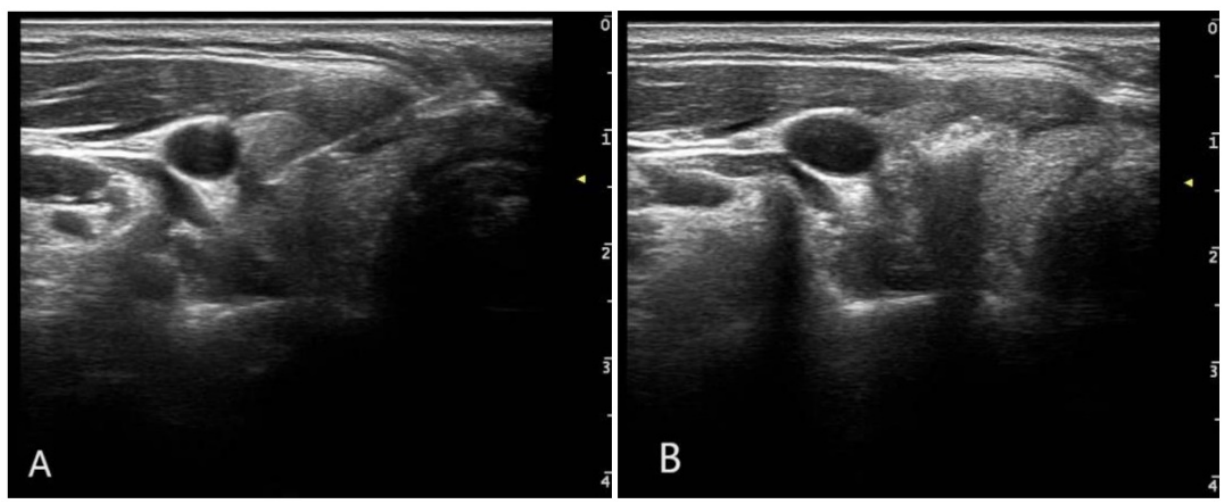

Figure 2. Images of radio frequency ablation (RFA). A. RFA needle was puncturing into the nodules. B. After turning on the RFA machine, gasification could be seen around the electrode. 

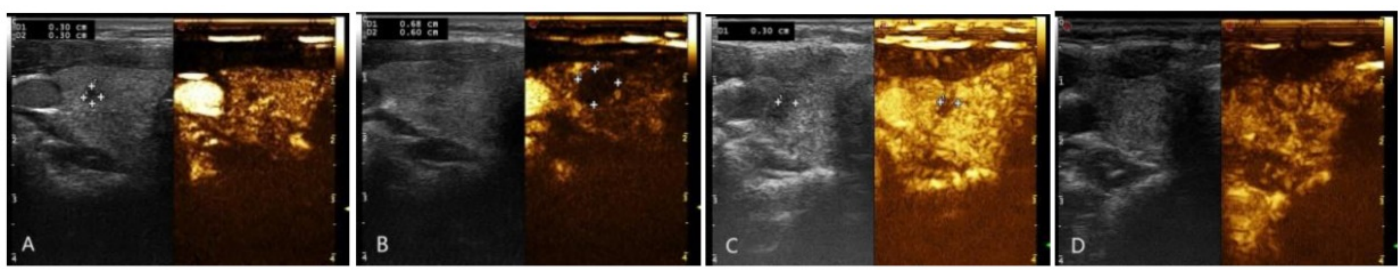

Figure 3. Changes of the nodule volume before and after RFA treatment, and real-time evaluation was carried out with contrast-enhanced ultrasound. A: before ablation. B: right after ablation. C: one month postoperatively. D. three months postoperatively: ablated lesion was completed absorbed.

\section{Discussion}

For a long time, surgical resection has been the traditional treatment of benign thyroid nodules.Although the therapeutic efficacy of surgical resection is good as it can remove the tumor, it hashuge affectson thyroid function after surgery.Some scholars found that postoperative hypothyroidism after resection of thyroid side lobe might happen in $5-49 \%$ of patients, recurrent laryngeal nerve injury in $0.2-1.1 \%$ of patients, permanent hypocalcemia in $1 \%$ of patients[17-20]. Afterlong term follow-up of 1051 cases who had received hemithyroidectomy, Vaiman $M$ et al. [21] found that $28 \%$ of the patients had to take thyroxine after surgery. Meanwhile, some patients refused surgery due to the permanent scar on the neck that were hard to eliminate. In recent years, endoscopic thyroid surgeries, such as neck-scar-free surgeries, are conducted in clinical practice [22-24], but its damage of the surrounding tissues cannot be ignored, as it may cause larger damage to its surroundings; in addition, this surgery method also depends on the location and nature of the thyroid nodules, and not all nodules are suitable for these kinds of treatments. Therefore, clinicians continue to explore new minimally invasive treatment methods to compensate for the deficiency of traditional treatment methods. In recent years, minimally invasive treatment for thyroid nodules has been made possible with the rapid development of ablation technologies. Ethanolablation and laser ablation have been applied for thyroid nodules and have achieved satisfactory results [25, 26]. Kim JH et al. [27] believed that ethanol injection was more suitable for treating cystic thyroid nodules. Meanwhile, some studies reported that the therapeutic efficacy of laser ablation for benign thyroid nodules were more precise [28, 29].

Because RFA has the advtanges of minimal invasivion, simple operation,controllability in ablation range, stability and reliabilty[13, 30], it has been widely used in minimally invasive treatment of malignant liver cancer[31, 32]. RFA is a new way for treating thyroid nodules. Many studies suggested that RFA for treating benign thyroid nodules and recurrent thyroid cancer is safe and reliable with significant efficacy [13-15].

RFA for treating benign thyroid nodules had significant efficacy, and both its volume reduction ratio (VRR) and complete ablation rate (CAR) are high, thus it can meet the demands of patients. Studies[33-35] had showed that volume reduction rate of benign thyroid nodules after complete ablationcould be more than 50\%, and long-term follow-ups found thatvolume reduction rate of some benign thyroid nodulescould even reach $75-97 \%$. Our center's study data showed that, volume reduction rate of thyroid nodules could reach $85.54 \%$ at three months after RFA, which was consistent with foreign studies. In terms of complete ablation rate, CEUS followed-ups showed that 376 nodules were completely ablated, and CAR is $98.95 \%$. Because the four partly ablated nodules were adjacent to trachea and recurrent laryngeal nerve with relative large volume, explanations were given to patients before treatment that only partial ablations were conducted to reduce the size of the tumors in order to relive compression symptom. After ablation, the compression symptom was relived, and patients were satisfied with the treatment results. And a secondary ablation could be performed according to the absorption of the ablation location and the growth of the residual nodules. Among them, two patients received the second treatment of RFA about 6 months after ablation, because of the completely absorption of the ablation foci and the growth trend of the residual foci. However, there was no significant change of the residual foci in the other two cases. And they had not received the second ablation.

For safety concerns of the treatment, our medical center had applied RFA under general anesthesia and endotracheal intubation. Some studies reported that [36], RFA of benign thyroid nodules could be safely performed under local anesthesia. A retrospective analysis of the data from our center found that during the RFA, one case had rapid expansion of the thyroid gland and duct, in which the volume of the thyroid glanddouble expanded. Due to the administration of intravenous bolus of methylprednisolone before ablation,volume of thyroid gradually returned to 
preoperative level withdisappearance of duct expansion after one hour.After analysis, it might be related to heat generated by electrode nodule during RFA of the thyroid, which could make the inner tissue of nodule generate coagulation necrosis-"hot ball". The heat would stimulate surrounding tissue causing transient rapid secretion of surrouding gland tissue, thus the shape of thyroid gland rapidly expanded, leading to "quasi-thyroid storm". Hormone is the best treatment option, and intubation helped to avoid feeling of suffocation caused by enlarged thyroid compressing trachea in this case.In addition,general anesthesia help tocompletely avoid side effects of local anesthesia, such as patients' discomfort, pain, vagovagal reflex, andcough[36], thus improving patients' medical experience.

RFA is safe and controllable. Different from majority of scholars using temperature mode, ourcenter adopted power control mode with low-power, short-time, multi-point, multi-planar ablation, making ablation range more accurate and controllable. There were no severe complications, such as serious recurrent laryngeal nerve injury, tracheal injury, bleeding, hematoma, skin lesions nor burns in our group. Only one case had temporary vocal cord paralysis displaying as hoarseness and coughing during drinking postoperatively. Coughing during drinking symptom disappeared two weeks after ablation while hoarseness disappeared two months after ablation, which was similar to reports of some studies. Some scholars reported that some complications occurred after RFA of thyroid nodule were reversible, and patients could get recovery in long-term follow-ups [34, 37-39]. This was consistent with our center's conclusion.

RFA adopted19G radiofrequency electrode, which only left needle holes that were smaller than transfusion needle in patient's neck. It is not only innovative comparing to traditional surgery, but also improved by meeting patient's esthetic demands completely.

\section{Conclusions}

Ultrasound-guided percutaneous RFA for treating benign thyroid nodules have the advantages of definite efficacy, significant volume reduction of ablation lesion, high absorption rate, less damage to surrounding normal tissue, and low complication rate (most complications are reversible). There is no surgical incision, and it can meet patient's esthetic demands to the maximum degree, thus RFA is suitable to use as the first-choice treatment for benign thyroid nodules, and it can replace surgery treatment of benign thyroid nodules in some degree.

\section{Abbreviations}

RFA: radiofrequency ablation; FNA: fine needle aspiration biopsy; VRR: volume reduction ratio; CAR: complete ablation rate.

\section{Acknowledgements}

Xiaoyin Tang collected the data of the patients, designed the pipeline of the analysis and drafted the manuscript. Bo Zhai and Ping Li conceived and coordinated the overall study and revised the manuscript. All authors read and approved the final manuscript.

\section{Competing Interests}

The authors have declared that no competing interest exists.

\section{References}

1. Singer PA, Cooper DS, Daniels GH, Ladenson PW, Greenspan FS, Levy EG, et al. Treatment guidelines for patients with thyroid nodules and well-differentiated thyroid cancer. American Thyroid Association. Archives of internal medicine. 1996; 156: 2165-72.

2. Tan GH, Gharib H. Thyroid incidentalomas: management approaches to nonpalpable nodules discovered incidentally on thyroid imaging. Annals of internal medicine. 1997; 126: 226-31.

3. Guth S, Theune U, Aberle J, Galach A, Bamberger CM. Very high prevalence of thyroid nodules detected by high frequency $(13 \mathrm{MHz})$ ultrasound examination. European journal of clinical investigation. 2009; 39: 699-706.

4. Smith-Bindman R, Miglioretti DL, Johnson E, Lee C, Feigelson HS, Flynn M, et al. Use of diagnostic imaging studies and associated radiation exposure for patients enrolled in large integrated health care systems, 1996-2010. Jama. 2012; 307: 2400-9.

5. Gharib H, Papini E. Thyroid nodules: clinical importance, assessment, and treatment. Endocrinology and metabolism clinics of North America. 2007; 36: 707-35, vi.

6. Hegedus L. Clinical practice. The thyroid nodule. The New England journal of medicine. 2004; 351: 1764-71.

7. Kihara M, Hirokawa M, Masuoka H, Yabuta T, Shindo H, Higashiyama T, et al. Evaluation of cytologically benign solitary thyroid nodules by ultrasonography: a retrospective analysis of 1877 cases. Auris, nasus, larynx. 2013; 40: 308-11.

8. Lee S, Skelton TS, Zheng F, Schwartz KA, Perrier ND, Lee JE, et al. The biopsy-proven benign thyroid nodule: is long-term follow-up necessary? Journal of the American College of Surgeons. 2013; 217: 81-8; discussion 8-9.

9. Chen AY, Bernet VI, Carty SE, Davies TF, Ganly I, Inabnet WB, 3rd, et al. American Thyroid Association statement on optimal surgical management of goiter. Thyroid : official journal of the American Thyroid Association. 2014; 24: 181-9.

10. Hegedus L, Bonnema SJ, Bennedbaek FN. Management of simple nodular goiter: current status and future perspectives. Endocrine reviews. 2003; 24: 102-32.

11. Gao J, Ke S, Ding XM, Zhou YM, Qian XJ, Sun WB. Radiofrequency ablation for large hepatic hemangiomas: initial experience and lessons. Surgery. 2013; 153: 78-85.

12. Fan RF, Chai FL, He GX, Wei LX, Li RZ, Wan WX, et al. Laparoscopic radiofrequency ablation of hepatic cavernous hemangioma. A preliminary experience with 27 patients. Surgical endoscopy. 2006; 20: 281-5.

13. Jeong $W K$, Baek JH, Rhim $\mathrm{H}$, Kim YS, Kwak MS, Jeong HJ, et al. Radiofrequency ablation of benign thyroid nodules: safety and imaging follow-up in 236 patients. European radiology. 2008; 18: 1244-50.

14. Monchik JM, Donatini G, Iannuccilli J, Dupuy DE. Radiofrequency ablation and percutaneous ethanol injection treatment for recurrent local and distant well-differentiated thyroid carcinoma. Annals of surgery. 2006; 244: 296-304.

15. Na DG, Lee JH, Jung SL, Kim JH, Sung JY, Shin JH, et al. Radiofrequency ablation of benign thyroid nodules and recurrent thyroid cancers: consensus statement and recommendations. Korean journal of radiology. 2012; 13: $117-25$.

16. Che Y, Jin S, Shi C, Wang L, Zhang X, Li Y, et al. Treatment of Benign Thyroid Nodules: Comparison of Surgery with Radiofrequency Ablation. AJNR American journal of neuroradiology. 2015; 36: 1321-5.

17. Farkas EA, King TA, Bolton JS, Fuhrman GM. A comparison of total thyroidectomy and lobectomy in the treatment of dominant thyroid nodules. The American surgeon. 2002; 68: 678-82; discussion 82-3. 
18. Wormald R, Sheahan P, Rowley S, Rizkalla H, Toner M, Timon C. Hemithyroidectomy for benign thyroid disease: who needs follow-up for hypothyroidism? Clinical otolaryngology : official journal of ENT-UK ; official journal of Netherlands Society for Oto-Rhino-Laryngology \& Cervico-Facial Surgery. 2008; 33: 587-91.

19. McHenry CR, Slusarczyk SJ. Hypothyroidisim following hemithyroidectomy: incidence, risk factors, and management. Surgery. 2000; 128: 994-8.

20. Bron LP, O'Brien CJ. Total thyroidectomy for clinically benign disease of the thyroid gland. The British journal of surgery. 2004; 91: 569-74.

21. Vaiman M, Nagibin A, Hagag P, Kessler A, Gavriel H. Hypothyroidism following partial thyroidectomy. Otolaryngology--head and neck surgery : official journal of American Academy of Otolaryngology-Head and Neck Surgery. 2008; 138: 98-100.

22. Udomsawaengsup S, Navicharern P, Tharavej C, Pungpapong SU. Endoscopic transaxillary thyroid lobectomy: flexible vs rigid laparoscope. Journal of the Medical Association of Thailand $=$ Chotmaihet thangphaet. 2004; 87 Suppl 2: S10-4.

23. Materazzi G, Fregoli L, Manzini G, Baggiani A, Miccoli M, Miccoli P. Cosmetic result and overall satisfaction after minimally invasive video-assisted thyroidectomy (MIVAT) versus robot-assisted transaxillary thyroidectomy (RATT): a prospective randomized study. World journal of surgery. 2014; 38: 1282-8.

24. Karakas E, Steinfeldt T, Gockel A, Schlosshauer T, Dietz C, Jager J, et al. Transoral thyroid and parathyroid surgery--development of a new transoral technique. Surgery. 2011; 150: 108-15.

25. Sung JY, Baek JH, Kim YS, Jeong HJ, Kwak MS, Lee D, et al. One-step ethanol ablation of viscous cystic thyroid nodules. AJR American journal of roentgenology. 2008; 191: 1730-3.

26. Papini E, Guglielmi R, Bizzarri G, Pacella CM. Ultrasound-guided laser thermal ablation for treatment of benign thyroid nodules. Endocrine practice : official journal of the American College of Endocrinology and the American Association of Clinical Endocrinologists. 2004; 10: 276-83.

27. Kim JH, Lee HK, Lee JH, Ahn IM, Choi CG. Efficacy of sonographically guided percutaneous ethanol injection for treatment of thyroid cysts versus solid thyroid nodules. AJR American journal of roentgenology. 2003; 180: 1723-6.

28. Spiezia S, Vitale G, Di Somma C, Pio Assanti A, Ciccarelli A, Lombardi G, et al. Ultrasound-guided laser thermal ablation in the treatment of autonomous hyperfunctioning thyroid nodules and compressive nontoxic nodular goiter. Thyroid : official journal of the American Thyroid Association. 2003; 13: 941-7.

29. Dossing H, Bennedbaek FN, Karstrup S, Hegedus L. Benign solitary solid cold thyroid nodules: US-guided interstitial laser photocoagulation--initial experience. Radiology. 2002; 225: 53-7.

30. Cibas ES, Ali SZ. The Bethesda System for Reporting Thyroid Cytopathology. Thyroid : official journal of the American Thyroid Association. 2009; 19: 1159-65.

31. Kang TW, Rhim H, Kim EY, Kim YS, Choi D, Lee WJ, et al. Percutaneous radiofrequency ablation for the hepatocellular carcinoma abutting the diaphragm: assessment of safety and therapeutic efficacy. Korean journal of radiology. 2009; 10: 34-42.

32. Lencioni R, Cioni D, Bartolozzi C. Percutaneous radiofrequency thermal ablation of liver malignancies: techniques, indications, imaging findings, and clinical results. Abdominal imaging. 2001; 26: 345-60.

33. Sung JY, Baek JH, Kim KS, Lee D, Yoo H, Kim JK, et al. Single-session treatment of benign cystic thyroid nodules with ethanol versus radiofrequency ablation: a prospective randomized study. Radiology. 2013; 269: 293-300.

34. Baek JH, Moon WJ, Kim YS, Lee JH, Lee D. Radiofrequency ablation for the treatment of autonomously functioning thyroid nodules. World journal of surgery. 2009; 33: 1971-7.

35. Lee JH, Kim YS, Lee D, Choi H, Yoo H, Baek JH. Radiofrequency ablation (RFA) of benign thyroid nodules in patients with incompletely resolved clinical problems after ethanol ablation (EA). World journal of surgery. 2010; 34: 1488-93.

36. Ugurlu MU, Uprak K, Akpinar IN, Attaallah W, Yegen C, Gulluoglu BM. Radiofrequency ablation of benign symptomatic thyroid nodules: prospective safety and efficacy study. World journal of surgery. 2015; 39: 961-8.

37. Spiezia S, Garberoglio R, Milone F, Ramundo V, Caiazzo C, Assanti AP, et al. Thyroid nodules and related symptoms are stably controlled two years after radiofrequency thermal ablation. Thyroid : official journal of the American Thyroid Association. 2009; 19: 219-25.

38. Deandrea M, Limone P, Basso E, Mormile A, Ragazzoni F, Gamarra E, et al. US-guided percutaneous radiofrequency thermal ablation for the treatment of solid benign hyperfunctioning or compressive thyroid nodules. Ultrasound in medicine \& biology. 2008; 34: 784-91.

39. Kim YS, Rhim H, Tae K, Park DW, Kim ST. Radiofrequency ablation of benign cold thyroid nodules: initial clinical experience. Thyroid : official journal of the American Thyroid Association. 2006; 16: 361-7. 